Bond University

Research Repository

\title{
Effects of caffeine on cognitive and autonomic measures in heavy and light caffeine consumers
}

Lyvers, Michael; Brooks, Janine; Matica, Deborah

Published in:

Australian Journal of Psychology

DOI:

10.1080/00049530410001688119

Licence:

Other

Link to output in Bond University research repository.

Recommended citation(APA):

Lyvers, M., Brooks, J., \& Matica, D. (2004). Effects of caffeine on cognitive and autonomic measures in heavy and light caffeine consumers. Australian Journal of Psychology, 56(1), 33-41.

https://doi.org/10.1080/00049530410001688119

\section{General rights}

Copyright and moral rights for the publications made accessible in the public portal are retained by the authors and/or other copyright owners and it is a condition of accessing publications that users recognise and abide by the legal requirements associated with these rights.

For more information, or if you believe that this document breaches copyright, please contact the Bond University research repository coordinator. 


\title{
Bond University
}

\section{ePublications@bond}

$1-1-2004$

\section{Effects of caffeine on cognitive and autonomic measures in heavy and light caffeine consumers}

\author{
Michael Lyvers \\ Bond University, michael_lyvers@bond.edu.au \\ Janine Brooks \\ Bond University \\ Deborah Matica \\ Bond University
}

Follow this and additional works at: http://epublications.bond.edu.au/hss_pubs

Part of the Psychology Commons

\section{Recommended Citation}

Michael Lyvers, Janine Brooks, and Deborah Matica. (2004) "Effects of caffeine on cognitive and autonomic measures in heavy and light caffeine consumers" ,, .

http://epublications.bond.edu.au/hss_pubs/17 


\title{
Effects of caffeine on cognitive and autonomic measures in heavy and light caffeine consumers
}

\author{
MICHAEL LYVERS, JANINE BROOKS, \& DEBORAH MATICA
}

Department of Psychology, School of Humanities and Social Sciences, Bond University, Gold Coast, Queensland, Australia

\begin{abstract}
Caffeine effects on arousal and cognition were assessed in relation to habitual caffeine intake. After drinking either decaffeinated coffee or decaffeinated coffee plus $300 \mathrm{mg}$ caffeine, 22 heavy caffeine consumers (HCCs) and 26 light caffeine consumers (LCCs) were examined on various cognitive, autonomic, and anxiety measures. In LCCs only, caffeine significantly improved performance of the Wisconsin Card Sorting Test, and significantly increased state anxiety scores. Caffeine significantly increased spontaneous skin conductance responses in HCCs and LCCs alike. The HCCs and LCCs did not differ on measures of trait anxiety or neuroticism. Results are discussed in terms of the cognitive enhancing and nonspecific arousing effects of caffeine in relation to caffeine tolerance.
\end{abstract}

Keywords: Anxiety, arousal, caffeine, cognition, skin conductance.

\section{Effects of caffeine on cognitive and autonomic measures in heavy and light caffeine consumers}

Caffeine is the most widely used and accepted psychoactive drug in the world. In the USA, estimates of the daily amount of caffeine consumed range from 3 to $7 \mathrm{mg} / \mathrm{kg}$ (Barone \& Roberts, 1996), and yearly consumption of more than $10 \mathrm{~kg} /$ person has been recorded in some Scandinavian countries (D'Amicis \& Viani, 1993; Gilbert, 1976). Popular beverages such as coffee, tea, and cola drinks are consumed both for their flavour and for the mild psychostimulant effects of the drug they contain (Daly, 1998). The ubiquitous nature of caffeine raises questions as to caffeine's physiological and cognitive actions as well as the motives for habitual caffeine use.

Relief of withdrawal has been proposed as a common motive for habitual ingestion of caffeine (Daly \& Fredholm, 1998; Garrett \& Griffiths, 1998; Hughes, Oliveto, Bickel, Higgins, \& Badger, 1993; Nehlig, 1999). Minor signs of physical dependence can develop after just three consecutive days of moderate caffeine consumption ( $300 \mathrm{mg} /$ day) (Evans \& Griffiths, 1999). Withdrawal signs may be evident when regular caffeine consumers are required to be caffeine abstinent for only a few hours past their normal overnight abstinence (Lane, 1997; Phillips-Bute \& Lane, 1998; Rogers \& Dernoncourt, 1998), with headache and fatigue being the most prominent and persistent symptoms (Heishman \& Henningfield, 1992; Hughes et al., 1993; Richardson, Rogers, Elliman, \& O'Dell, 1995). Failure to control for habitual level of caffeine consumption may have contributed to the somewhat mixed findings from previous research on the cognitive and psychomotor effects of caffeine. Many studies have reported caffeine-related enhancement of performance (Bättig \& Buzzi, 1986; Hindmarch, Quinlan, Moore, \& Parkin, 1998; Kenemans \& Verbaten, 1998; Rees, Allen, \& Lader, 1999; Robelin \& Rogers, 1998; Smith, Kendrick, Maben, \& Salmon, 1994; Warburton, 1995; also see review by Rusted, 1994), whereas other studies have reported no significant improvement (Edwards, Brice, Craig, \& Penri-Jones, 1996; Hertz, 1999; James, 1998; Loke, 1988, 1990) or even a decrement in performance following caffeine (Erikson et al., 1985; Foreman, Barraclough, Moore, Mehta, \& Madon, 1989). James (1997) cautions that some of the 
reported facilitation effects of caffeine may in fact be restoration effects following the reversal of caffeine withdrawal.

One of us (Lyvers) has previously used certain cognitive and autonomic correlates of prefrontal cortical functioning to characterise the acute and/or chronic effects of various abused drugs, including alcohol (Lyvers \& Maltzman, 1991a,b), nicotine (Lyvers, Maltzman \& Miyata, 1994, Lyvers \& Miyata, 1993), and methadone (Lyvers \& Yakimoff, 2003). Measures included the Wisconsin Card Sorting Test (WCST) and a psychophysiological paradigm assessing skin conductance responses (SCRs). Although each drug produced a unique profile of changes on these measures, findings were generally consistent with the notion that acute (alcohol) or chronic (nicotine, methadone) use of these drugs may significantly alter indices of prefrontal cortex functioning. For example, in social drinkers a moderate dose of alcohol $[0.05 \%$ blood alcohol level (BAL)]. selectively increased the percentage of WCST perseverative errors (Lyvers \& Maltzman, 1991b), reflecting the tendency to persist with a previously reinforced but currently inappropriate sorting strategy. This measure is particularly sensitive to acute frontal lobe damage or dysfunction (Bornstein, 1986; Drewe, 1974; Heaton, Chelune, Talley, Kay, \& Curtiss, 1993; Malloy \& Richardson, 1994; Milner, 1964; Mountain \& Snow, 1993; Stuss et al., 1983). By contrast, nonperseverative errors were unaffected by alcohol. In heavy smokers, $12 \mathrm{hrs}$ of nicotine abstinence selectively increased percent perseverative errors without affecting nonperseverative errors, whereas smoking a cigarette restored WCST performance to nonsmoker levels. A mesocortical dopaminergic mechanism of such drug effects has been proposed (Lyvers, 2000). The present study sought to determine whether a moderate dose of caffeine might also affect cognitive and autonomic correlates of prefrontal cortical functioning in a selective manner. Given the previous findings that such indices were mildly disrupted by short-term abstinence rather than intoxication in heavy smokers and in chronic users of methadone, the responses of heavy and light coffee consumers to caffeine were compared to determine whether chronic high intake of caffeine might be associated with a different response to the drug (such as acute tolerance or relief of withdrawal deficits) than would occur in light users.

Although the WCST has not previously been used to examine caffeine's effects on cognition, another test that is sometimes regarded as a "frontal lobe" task, the Stroop Colour-Word Test (SCWT), has been used in several caffeine studies. The SCWT places high demands on participants to selectively focus on one type of information while simultaneously ignoring another (MacLeod, 1991). Results from caffeine studies using the SCWT have been mixed, with caffeine resulting in improvement (Hasenfratz \& Bättig, 1992; Kenemans, Wieleman, Zeegers, \& Verbaten, 1999; Patat et al., 2000; Riedel et al., 1995), hindrance (Foreman et al., 1989), or no significant effect on performance (Edwards et al., 1996). The present study compared heavy and light caffeine users on caffeine-related SCWT performance in an attempt to resolve such discrepancies from previous work, in light of the hypothesis of James (1997), cited earlier.

Evoked and spontaneous SCRs were also compared across caffeine user groups and consumption conditions to determine whether caffeine would affect such measures in line with previous findings for alcohol (Lyvers \& Maltzman, 1991a) and nicotine (Lyvers \& Miyata, 1993). Caffeine levels as low as those typically present in one cup of coffee have been shown to increase autonomic nervous system activity, resulting in a number of behavioural and physiological changes (Quinlan, Lane, \& Aspinall, 1997). The latter include cerebral vasoconstriction (Mathew \& Wilson, 1985), decreases in peripheral skin temperature (Bruce, Scott, Lader, \& Marks, 1986; Quinlan et al., 1997), and increases in systolic blood pressure (Cameron, Modell, \& Hariharan, 1990), startle eyeblink responses (Andrews, Blumenthal, \& Flaten, 1998), electroencephalogram (EEG) signs of arousal (Bruce et al., 1986; Bruce, Scott, Shine \& Lader, 1992; Newman, Stein, Trettau, Coppola, \& Uhde, 1992), and tonic skin conductance levels (SCL) as well as SCR amplitude and frequency (Bruce et al., 1986; Davidson \& Smith, 1991; Zahn \& Rapoport, 1987). Given these previous findings, nonselective psychophysiological effects of caffeine were anticipated in the present study in line with the drug's hypothesised nonspecific enhancement of autonomic arousal.

Finally, the present study provided an opportunity to examine the possible role of anxious personality traits in caffeine consumption. Because persons with high levels of neuroticism (Meyer, 1996) or pathological anxiety (Boulenger, Uhde, Wolff, \& Post, 1984; Bruce \& Lader, 1986; Charney, Heninger, \& Jatlow, 1985) have been reported to suffer anxiogenic effects of caffeine consumption, we tentatively expected that such individuals would tend not to be heavy caffeine consumers. We also anticipated that light caffeine users would tend to report an anxiogenic response to $300 \mathrm{mg}$ caffeine, whereas heavy caffeine users would not, due to differences in either dispositional or acquired tolerance to such effects. 


\section{Method}

\section{Participants}

The subjects were 48 paid volunteers (20 male and 28 female), including 22 heavy caffeine consumers (HCCs), defined as persons who usually consume a minimum of $400 \mathrm{mg}$ caffeine per day, and 26 light caffeine consumers (LCCs), defined as persons who normally consume no more than $500 \mathrm{mg}$ caffeine per week from all sources. The HCC and LCC groups were defined in accord with previous recommendations for standardisation of such groups in caffeine studies (Bruce \& Lader, 1986). To determine their habitual level of caffeine consumption, participants were first interviewed by telephone and subsequently completed a caffeine use questionnaire. Once classified as HCC or LCC, assignment to caffeine or placebo condition was random. This resulted in 11 $\mathrm{HCCs}$ given caffeine, $11 \mathrm{HCCs}$ given placebo, 13 LCCs given caffeine, and $13 \mathrm{LCCs}$ given placebo. A fully between-subjects design was employed because of the strong effects of repeated testing on both WCST performance (Lyvers \& Maltzman, 1991b) and SCRs (Lyvers, Boyd, \& Maltzman, 1988), which would likely obscure caffeine effects or complicate their interpretation. To qualify for inclusion in the study, participants were required to (a) be between the ages of 18 to 35 years; (b) be nonsmokers, to avoid nicotine effects on WCST and SCR measures (Lyvers \& Miyata, 1993; Lyvers et al., 1994); (c) report typical caffeine intake that met the above criteria for either HCC or LCC; (d) have no prior history of treatment or arrest for illicit drug- or alcohol-related problems; and (e) normally consume no more than 14 standard alcoholic drinks per week. To recruit subjects, flyers were posted on the campuses of Bond and Griffith-Gold Coast Universities and an email request was sent to all Bond students. Additionally, articles in two local newspapers explained the study and called for volunteers. Subjects were paid $\$ 20$ for their participation in this study, which was approved by the Human Research Ethics Committee of Bond University. Spontaneous SCR data were missing from three subjects (one LCC/caffeine male subject; two LCC/placebo female subjects) due to computer errors, leaving data from 45 subjects for analysis of spontaneous SCRs. One male LCC/placebo subject was colourblind and hence was unable to perform the WCST and Stroop tests, leaving $12 \mathrm{LCC} /$ placebo subjects for the neuropsychological phase of the study.

\section{Materials}

Psychophysiological measurement. The Bioview series $\mathrm{V}$ recording system (Zencor, Melbourne, Vic., Australia) was utilised to measure participants'
SCRs. All measurements were recorded and saved by an IBM-compatible computer. Silver/silver chloride SCR electrodes were attached to the middle and fourth fingers of each subject's nonpreferred hand via velcro straps. A $10-\mathrm{min}$ cassette recording of three distinct tones was played at approximately $60 \mathrm{~dB}$ through a Sony mini hi-fi system. The stimuli evoking SCRs were a $1000-\mathrm{Hz}$ tone presented 42 times, and a $2000-\mathrm{Hz}$ tone and $500-\mathrm{Hz}$ tone, which were each presented 7 times. The tones occurred in a random order and the inter-stimulus interval (ISI) varied from 8 to $12 \mathrm{~s}$. The largest increase of at least $0.05 \mu \mathrm{S}$ that occurred within a response window of $1-5 \mathrm{~s}$ after each tone was defined as the evoked SCR. A count of spontaneous SCRs, defined as increases in conductance of at least $0.25 \mu \mathrm{S}$, was taken during the final $10 \mathrm{~min}$ of the electrode stabilisation period before tones were presented, as a measure of nonspecific arousal.

Questionnaires. The following questionnaires were administered to all subjects: (a) the Eysenck Personality Questionnaire Revised (EPQ-R) (Eysenck \& Eysenck, 1991), which measures the personality traits of extraversion and neuroticism; (b) the Spielberger Trait/State Anxiety Inventory (STAI) (Spielberger, Gorsuch, Lushene, Vagg, \& Jacobs, 1983), which assesses both acute (state) and stable (trait) anxiety; and (c) the Beck Anxiety Inventory (BAI) (Beck \& Steer, 1993), which is another index of trait anxiety, because BAI scores are significantly correlated with other reliable and valid anxiety measures (Beck \& Steer, 1991, 1993; Osman, Barrios, Aukes, .. Osman, \& Markway, 1993).

Wisconsin Card Sorting Test - computer version. This neuropsychological test targets the ability to identify relevant abstract categories and to shift response strategies according to changing demands. It is often used to diagnose frontal lobe dysfunction (Anderson, Damasio, Jones, \& Tranel, 1991; Bornstein, 1986). Brain imaging studies indicate that the prefrontal cortex is the primary area activated during this test (Berman et al., 1995; Smith, Perdices, O'Sullivan, Large, \& Barrett, 1997). The computer version of the WCST (Heaton et al., 1993), used in the present study, places the same requirements on subjects as the manual version and provides a number of performance measures. For the purposes of the present study, the following measures were used: percentage of total responses that were errors (\%TE); percentage perseverative errors (\%PE), the percentage of responses that were errors due to perseveration (i.e., using a previously correct but currently inappropriate sorting strategy); and per- 
centage nonperseverative errors (\%NPE), the percentage of responses that were errors not due to perseveration. The \%PE served as the criterion index of frontal lobe functioning (Mountain \& Snow, 1993), with \%NPE serving as a control for nonspecific effects.

Stroop Colour-Word Test. In line with Stroop's original conceptual framework (Henik, 1996), the Stroop effect (SE) was measured as the difference in colour naming reaction time between a control of coloured $\mathrm{x}$ strings and colour words printed in incongruent colours. Stimuli were presented in 4 columns and 12 rows, evenly spaced on white, A3size sheets. Lowercase words or $\mathrm{x}$ strings were printed in size 52 serif font (Times New Roman). Four display colours were used for each condition (red, blue, green, pink). Condition A was a control condition with $\mathrm{x}$ strings printed equally often in each of the four colours. Condition B used four words naming colours (red, blue, green, pink); however, the words were printed only in incongruent colours. This led to 12 different possibilities of word/colour presentations for Condition B, with each being presented four times. For both conditions the $\mathrm{x}$ strings and incongruent coloured words were counterbalanced across columns and rows as much as possible.

\section{General procedures}

The 2-hr experimental session was conducted individually in a quiet, air-conditioned room. Appointments were scheduled for commencement between 8:00 am and 11:00 am. Prior to their appointment time, participants were told to abstain from caffeine, alcohol, and illicit drugs for $15 \mathrm{hr}$, and food for $3 \mathrm{hr}$. Upon their arrival, all participants were intensively queried about their adherence to the abstinence requirements. A breathalyser was used to determine that no alcohol had been recently consumed. No violations of any abstinence requirement were indicated.

Participants completed a form assessing the amount and sources of caffeine that they would typically consume in a week. After reading and signing an informed consent form, they were randomly assigned to receive either caffeine or placebo. All participants were blind to their experimental condition, and drank two cups of instant decaffeinated coffee in a 15 -min period. Those in the caffeine condition had $300 \mathrm{mg}$ caffeine added to their drinks ( $150 \mathrm{mg} / \mathrm{cup}$ ). Participants then had SCR electrodes attached to the middle and fourth fingers of their nonpreferred hand by way of velcro straps. A 30-min electrode stabilisation/caffeine absorption period then ensued during which participants were instructed to keep their nonpreferred hands palms down and be as still as possible to prevent electrolyte leakage. During this time participants completed the BAI, the EPQ and the STAI, after which they had the option to read a magazine. Absorption of caffeine from the gastrointestinal tract is virtually complete after $45 \mathrm{~min}$, and peak plasma levels occur within $2 \mathrm{hr}$ (Feldman, Meyer \& Quenzer, 1997; Julien, 1996), hence active levels of caffeine were assumed to be maintained throughout the testing phase. Spontaneous SCRs were recorded during the last 10 min of the absorption period.

Participants then listened to the tone series. They were instructed to press the spacebar on the computer once whenever the signal tone was played, which was either the $500-\mathrm{Hz}$ or $2000-\mathrm{Hz}$ tone depending on their counterbalancing subgroup. A preview of all three tones was given before commencement of the 10-min recording period. One of the infrequent tones was a signal stimulus, whereas the other infrequent tone was a novel nonsignal stimulus, allowing independent measurement of SCRs evoked by stimulus novelty and stimulus significance. Following measurement of SCRs, participants performed the computerised version of the WCST. The last task for the participants was the SCWT. Participants were instructed to name the colour that each stimulus was printed in as quickly as possible. The order of naming was from left to right column across the page, and from top to bottom row. Participants were told that accuracy was crucial, therefore if a colour was wrongly named, either self-correction or correction on prompting was required before proceeding further. After receiving their instructions each participant was instructed to stand $1 \mathrm{~m}$ from where their first stimulus sheet was placed, covered from their view by a sheet of paper. On the start signal from the experimenter the subject began to identify the colours aloud. Each participant performed both conditions in this fashion, thus making a total of 96 colour identifications. Response times were recorded using a digital stopwatch with $0.01 \mathrm{~s}$ accuracy. Counterbalancing of conditions (control and incongruent) was used to control for practice effects.

\section{Results}

Data were analysed using the Statistical Package for the Social Sciences (SPSS) Version 10.00 for Windows (SPSS Inc., 1999). As expected, chisquare and one-way analyses of variance (ANOVA) revealed no significant differences between groups on the demographic variables (age, gender, body weight and years of education). 
Caffeine and Wisconsin Card Sorting Test performance

A between-subjects multivariate analysis of variance (MANOVA) was performed on the three selected WCST performance measures, \% TE, \%NPE, and $\%$ PE. Independent variables were typical caffeine consumption (HCC/LCC) and condition (caffeine/ placebo). The WCST variables were subjected to square root transformations prior to analysis in order to meet statistical assumptions. Mean untransformed group scores are displayed in Table I.

Caffeine subjects made a lower percentage of errors overall (\%TE) $(M=18.19)$ than did placebo subjects $(M=26.23), F(1,43)=4.30, p=.04$. Caffeine condition did not significantly influence scores on the remaining WCST measures. However, the interaction between typical caffeine consumption and caffeine condition was significant for all three measures: \% TE, $F(1,43)=6.37, p=.015 ; \% \mathrm{NPE}$, $F(1,43)=4.19, p=.047$; and $\% \mathrm{PE}, F(1,43)=5.42$, $p=.025$ (see Table I for the untransformed group means). Observed power was moderate at $.694, .517$ and .624, respectively. Tukey post hoc analysis revealed that LCC subjects' performance was significantly superior on each WCST measure in the caffeine condition compared to the placebo condition. No other comparisons were significant.

\section{Caffeine and Stroop Colour-Word Test performance}

A between-subjects ANOVA was conducted with SE as the dependent variable. Independent variables were typical caffeine consumption (HCC/LCC) and condition (caffeine/placebo). Results are presented in Table II. No significant main effects were found. The interaction approached significance, $F(1$, 43) $=3.31, p=.08$, reflecting a trend (see Table II) towards LCCs performing better on caffeine than on placebo.

Typical caffeine consumption in relation to anxiety and neuroticism

Planned independent $t$ tests were conducted to examine habitual caffeine use in relation to trait anxiety and neuroticism. The independent variable was typical caffeine consumption (HCC/LCC) and dependent variables were trait anxiety, as measured by STAI and BAI scores, and neuroticism as measured by the EPQ-R. Group means are shown in Table III. Contrary to predictions, no significant differences were found between LCCs and HCCs on measures of trait anxiety or neuroticism.

\section{Anxiogenic effect of acute caffeine consumption}

The expected significant interaction between typical caffeine consumption and caffeine condition was found using ANOVA on the STAI-S, $F(1,44)=4.46$, $p=.04$. As predicted, LCCs given caffeine reported significantly higher state anxiety $(M=39)$ than LCCs given placebo $(M=30.42), t(24)=1.79, p=.04$ (one-tailed). By contrast, HCCs did not significantly differ in state anxiety between caffeine $(M=31.18)$ and placebo $(M=35.91)$ conditions.

\section{Caffeine and evoked skin conductance responses}

Evoked SCR data were subjected to a mixed ANOVA, with typical caffeine consumption and condition as between-subject variables and tone stimulus (signal, novel nonsignal, common nonsignal) and trial block $(1-7)$ as within-subject variables. The dependent variable was evoked SCR magnitude. Due to the positive skew of the SCR data, square root and logarithmic transformations were performed. However, these transformations had no significant impact on the results. The

Table II. Stroop effect as a function of typical caffeine consumption and caffeine versus placebo

\begin{tabular}{lll}
\hline Group & Condition & SE (s) \\
\hline Light caffeine & Caffeine $(n=13)$ & 13.84 \\
consumers & Placebo $(n=12)$ & 22.00 \\
Heavy caffeine & Caffeine $(n=11)$ & 19.31 \\
consumers & Placebo $(n=11)$ & 18.06 \\
\hline
\end{tabular}

Note. $\mathrm{SE}=$ difference between control and incongruent stimulus conditions.

Table I. WCST scores for HCC and LCC on caffeine (300 mg) versus placebo

\begin{tabular}{|c|c|c|c|c|}
\hline \multirow[b]{2}{*}{ WCST measure } & \multicolumn{2}{|c|}{$\mathrm{LCC}$} & \multicolumn{2}{|c|}{$\mathrm{HCC}$} \\
\hline & $\begin{array}{l}\text { Caffeine } \\
(n=13)\end{array}$ & $\begin{array}{l}\text { Placebo } \\
(n=12)\end{array}$ & $\begin{array}{c}\text { Caffeine } \\
(n=11)\end{array}$ & $\begin{array}{l}\text { Placebo } \\
(n=11)\end{array}$ \\
\hline$\% \mathrm{TE}$ & 15.39 & 32.92 & 21.00 & 19.55 \\
\hline$\% \mathrm{PE}$ & 7.69 & 16.83 & 11.00 & 10.27 \\
\hline$\% \mathrm{NPE}$ & 7.54 & 15.92 & 10.00 & 9.27 \\
\hline
\end{tabular}

Note: $\mathrm{WCST}=\mathrm{W}$ isconsin Card Sorting Test; HCC $=$ heavy caffeine consumer; $\mathrm{LCC}=$ light caffeine consumer; $\% \mathrm{TE}=$ percentage total errors; $\% \mathrm{NPE}=$ percentage nonperseverative errors; $\% \mathrm{PE}=$ percentage perseverative errors. 
Table III. Anxiety and neuroticism in HCC and LCC

\begin{tabular}{|c|c|c|c|c|c|}
\hline Group & STAI-S & & STAI-T & BAI & EPQ-N \\
\hline $\mathrm{HCC}(n=22)$ & 33.55 & . & 40.82 & 10.59 & 13.14 \\
\hline $\operatorname{LCC}(n=26)$ & 35.04 & & 37.08 & 8.19 & 12.08 \\
\hline
\end{tabular}

Note. $\mathrm{HCC}=$ heavy caffeine consumer; LCC = light caffeine consumer; STAI-S = state anxiety as measured by Spielberger Trait/State Anxiety Inventory (STAI); STAI-T = trait anxiety as measured by STAI; BAI = anxiety as measured by Beck Anxiety Inventory; EPQ$\mathrm{N}=$ neuroticism as measured by Eysenck Personality Questionnaire Revised.

conservative Greenhouse-Geisser correction was used to test within-subject effects. Although there was the expected overall main effect of type of tone stimulus on evoked SCR magnitude, there were no effects of typical caffeine consumption or condition, and no interactions.

\section{Caffeine condition and spontaneous skin conductance responses}

A between-subjects ANOVA with typical caffeine consumption and condition as independent variables revealed a significant effect of condition on spontaneous SCRs, $F(1,43)=5.59, p=.03$. Participants who consumed caffeine exhibited significantly more spontaneous SCRs $(M=13.75)$ than those who received placebo $(M=6.19)$. There was no effect of typical caffeine consumption and no interaction.

\section{Discussion}

Unexpectedly, performance of LCCs on the WCST was significantly better after caffeine than after placebo, whereas HCCs showed no difference in performance between conditions. The nonselective effect on both perseverative and nonperseverative types of errors suggests a nonspecific cognitive enhancing effect of the drug in LCCs rather than a specific effect on cognitive processes mediated by the prefrontal cortex. The absence of any apparent effect of caffeine on WCST performance in HCCs suggests simple tolerance without abstinence or restorative effects, and can be contrasted with the restorative effects of nicotine on WCST performance in heavy smokers (Lyvers et al., 1994). The present findings thus did not support the hypothesis in James (1997) that improvement in performance following caffeine is generally due to reversal of withdrawal-induced deficits. Other recent evidence appears to be consistent with the present findings (see Rogers, Richardson, \& Dernoncourt, 1995). Perhaps only the most extreme caffeine consumers would show a withdrawal-related deficit in performance that is improved by caffeine. In any case, in the present study, a moderate dose of caffeine appeared to have a nonspecific cognitive enhancing effect in LCCs only.
Positive effects of caffeine on performance have most often been shown when performance was already degraded by factors such as fatigue, old age, or alcohol (van der Stelt \& Snel, 1998). Given that participants in the present study were normal, healthy, young volunteers, their cognitive performance was likely to have been close to optimum. White (1998) suggests that in such a sample there is little scope for improvement. However, the present findings for LCCs on the WCST suggest otherwise. This may be related to the cognitive task used in the present study. The WCST appears to be especially sensitive to drug effects, as indicated by previous work (Lyvers \& Maltzman, 1991b; Lyvers et al., 1994; Lyvers \& Yakimoff, 2003; Till \& Lyvers, 2000), and caffeine may affect any of a number of cognitive skills used on such a complex task as the WCST. Arnett et al. (1994) suggest that such skills include "selective, sustained, or divided attention; working or long-term memory; or speed of information-processing" (p. 424). However, the selective attention task used in the present study, the SCWT, showed no significant effect of caffeine. Although only approaching significance, the same trend was evident as with the WCST, that is, performance in LCCs, but not HCCs, appeared to be better on caffeine than placebo. As mentioned above, previous studies of caffeine and SCWT performance have yielded mixed results, suggesting that this task may not be as sensitive as the WCST to drug effects. Thus Lyvers and Yakimoff (2003) found significant effects of methadone on the WCST but not the SCWT, similar to the present results.

The SCR findings from the present study were also somewhat mixed but were partially consistent with a nonspecific arousing effect of caffeine. Although the evoked SCR paradigm replicated the robust finding of differential effects of novel versus signal tones on SCRs (Maltzman, 1979), caffeine did not significantly affect tone-evoked SCRs in the present study. However, the frequency of spontaneous SCRs was increased following caffeine ingestion in both HCC and LCC groups alike, consistent with a general caffeine-induced increase in nonspecific autonomic arousal that is relatively unaffected by tolerance. Similar results were reported by Zahn and Rapoport (1987), who observed 
that caffeine increased electrodermal activity in both heavy and light users alike. Skin conductance level has also been consistently shown to increase following caffeine (Bruce et al., 1986; Bruce et al., 1992; Davidson \& Smith, 1991).

Contrary to predictions of lower caffeine use in anxiety-prone individuals, no significant differences were found between HCC and LCC groups on measures of anxiety or neuroticism. This supports the assertion of Bättig (1985) that personality and anxiety are poor predictors of caffeine consumption. Other recent work also reported no relationship between trait anxiety and caffeine consumption (Stewart, Karp, Pihl, \& Peterson, 1997). The present study did, however, find that caffeine significantly elevated STAI-S scores in LCCs only. Thus caffeine increased state anxiety in LCCs but had no effect on state anxiety in HCCs, presumably due to either dispositional or acquired caffeine tolerance. By contrast, caffeine increased spontaneous SCRs, an autonomic index of arousal, in HCCs and LCCs alike. The same pattern of comparable autonomic but differential anxiogenic caffeine effects in heavy and light users was previously reported by Zahn and Rapoport (1987). Newman et al. (1992) found that $7 \mathrm{mg} / \mathrm{kg}$ caffeine increased anxiety in normal subjects who had not consumed caffeine for at least 2 weeks, whereas Quinlan et al. (1997) reported decreased anxiety following ingestion of caffeine and subsequent alleviation of withdrawal symptoms in heavy users who had abstained from caffeine. The present study, however, observed only caffeine-related increases in anxiety, and only in LCCs, similar to the findings of Zahn and Rapoport (1987).

In summary, the present findings suggest that caffeine may act as a mild, nonspecific cognitive enhancer in LCCs. Frequent caffeine use may offset any immediate beneficial effects of caffeine ingestion on cognition, but does not appear to be associated with significant withdrawal-related cognitive deficits in typical HCCs. Anxiogenic effects of caffeine were indicated in LCCs but not in HCCs, suggesting tolerance to such effects in the latter group especially given the absence of trait differences in anxiety or neuroticism between LCCs and HCCs in the present sample. If LCCs had exhibited higher levels of trait anxiety or neuroticism than HCCs, such individual differences could have predisposed LCCs to an anxiogenic caffeine response (Boulenger et al., 1984; Bruce \& Lader, 1986; Charney et al., 1985; Meyer, 1996), but the present results clearly favour a tolerance interpretation. In marked contrast to the cognitive and anxiogenic effects of caffeine, autonomic SCR responses to caffeine were similar in HCCs and LCCs, with no indication of tolerance. The nature of the apparent dissociation between autonomic and "higher" effects of caffeine in relation to habitual caffeine use is an issue to be addressed in future caffeine studies.

\section{References}

Anderson, S. W., Damasio, H., Jones, R. D., \& Tranel, D. (1991). Wisconsin Card Sorting Test performance as a measure of frontal lobe damage. Fournal of Clinical and Experimental Neuropsychology, 13, 909-922.

Arnett, P. A., Rao, S. M., Bernardin, M. S., Grafman, J., Yetkin, F. Z., \& Lobeck, L. (1994). Relationship between frontal lobe lesions and Wisconsin Card Sorting Test performance in patients with multiple sclerosis. Neurology, 44, 420-425.

Andrews, S. E., Blumenthal, T. D., \& Flaten, M. A. (1998). Effects of caffeine and caffeine-associated stimuli on the human startle eyeblink reflex. Pharmacology, Biochemistry and Behavior, 59, 39-44.

Barone, J. J., \& Roberts, H. R. (1996). Caffeine consumption. Food and Chemical Toxicology, 34, 119-126.

Bärtig, K. (1985). The physiological effects of coffee consumption. In M. N. Clifford. \& K. C. Willson (Eds.), Coffee: Botany, biochemistry, and production of beans and beverage (pp. 394437). London: Avi Publishing Company.

Bättig, K., \& Buzzi, R. (1986). Effect of coffee on the speed of subject-paced information processing. Neuropsychobiology, 16, $126-130$.

Beck, A. T., \& Steer, R. A. (1991). Relationship between the Beck Anxiety Inventory and the Hamilton Anxiety Rating Scale with anxious outpatients. Fournal of Anxiety Disorders, 5, 213-223.

Beck, A. T., \& Steer, R. A. (1993). Beck Anxiety Inventory: Manual. New York: The Psychological Corporation.

Berman, K. F., Ostrem, J. L., Randolph, C., Gold, J., Goldberg, T. E., Coppola, R. et al. (1995). Physiological activation of a cortical network during performance of the Wisconsin Card Sorting Test: A positron emission tomography study. Neuropsychologia, 33, 1027-1046.

Bornstein, R. A. (1986). Contributions of various neuropsychological measures to detection of frontal lobe impairment. International fournal of Clinical Neuropsychology, 8, 18-22.

Boulenger, J., Uhde, T. W., Wolff III, E. A., \& Post, R. M. (1984). Increased sensitivity to caffeine in patients with panic disorders. Archives of General Psychiatry, 41, 1067-1071.

Bruce, M. S., \& Lader, M. H. (1986). Caffeine: Clinical and experimental effects in humans. Human Psychopharmacology, 1 , 63-82.

Bruce, M., Scott, N., Lader, M., \& Marks, V. (1986). The psychopharmacological and electrophysiological effects of single doses of caffeine in healthy human subjects. British Fournal of Clinical Pharmacology, 22, 81-87.

Bruce, M., Scott, N., Shine, P., \& Lader, M. (1992). Anxiogenic effects of caffeine in patients with anxiety disorders. Archives of General Psychiatry, 49, 867-869.

Cameron, O. G., Modell, J. G., \& Hariharan, M. (1990). Caffeine and human cerebral blood flow: A positron emission tomography study. Life Sciences, 47, $1141-1146$.

Charney, D. S., Heninger, G. R., \& Jatlow, P. I. (1985). Increased anxiogenic effects of caffeine in panic disorders. Archives of General Psychiatry, 42, 233-243.

D'Amicis, A., \& Viani, R. (1993). The consumption of coffee. In S. Garattini (Ed.), Caffeine, coffee and health (pp. 1-16). New York: Raven Press.

Daly, J. W. (1998). Pharmacology of caffeine. In R. E. Tarter, R. T. Ammerman, \& P. J.Ott (Eds.), Handbook of substance abuse: Neurobehavioral pharmacology (pp. 97-110). New York: Plenum. 
Daly, J. W., \& Fredholm, B. B. (1998). Caffeine: An atypical drug of dependence. Drug and Alcohol Dependence, 51, 199-206.

Davidson, R. A., \& Smith, B. D. (1991). Caffeine and novelty: Effects on electrodermal activity and performance. Physiology and Behavior, 49, $1169-1175$.

Drewe, E.A. (1974). The effect of type and area of brain lesion on Wisconsin Card Sorting Test performance. Cortex, 10, 159 170.

Edwards, S., Brice, C., Craig, C., \& Penri-Jones, R. (1996). Effects of caffeine, practice, and mode of presentation on Stroop task performance. Pharmacology, Biochemistry and Behavior, 54, 309-315.

Erikson, G. C., Hager, L. B., Houseworth, C., Dungan, J., Petros, T., \& Beckwith, B. E. (1985). The effects of caffeine on memory for word lists. Physiology and Behavior, 35, 47-51.

Evans, S. M., \& Griffiths, R. R. (1999). Caffeine withdrawal: A parametric analysis of caffeine dosing conditions. Fournal of Pharmacology and Experimental Therapeutics, 289, 285-294.

Eysenck, H. J., \& Eysenck, B. G. (1991). Manual of the Eysenck Personality Scales (EPS Adult). London: Hodder \& Stoughton.

Feldman, R. S., Meyer, J. S., \& Quenzer, L. F. (1997). Principles of neuropsychopharmacology. Sunderland, MA: Sinauer.

Foreman, N., Barraclough, S., Moore, C., Mehta, A., \& Madon, M. (1989). High doses of caffeine impair performance of a numerical version of the Stroop task in men. Pharmacology, Biochemistry and Behavior, 32, 399-403.

Garrett, B. E., \& Griffiths, R. R. (1998). Physical dependence increases the relative reinforcing effects of caffeine versus placebo. Psychopharmacology, 139, 195-202.

Gilbert, R. M. (1976). Caffeine as a drug of abuse. In R. J. Gibbons, Y. Israel, H. Kalant, R. E. Popham, G. W. Schmidt \& R. G. Smart (Eds.), Research advances in alcohol and drug problems: Volume 3 (pp. 49-176). New York: Wiley and Sons.

Hasenfratz, M., \& Bättig, K. (1992) Action profiles of smoking and caffeine: Stroop effect, EEG, and peripheral physiology. Pharmacology, Biochemistry and Behavior, 42, 155-161.

Heaton, R. K., Chelune, G. J., Talley, J. L., Kay, G. G., \& Curtiss, G. (1993). Wisconsin Card Sorting Test: Computer Version-2. Odessa, FL: PAR.

Heishman, S. J., \& Henningfield, J. E. (1992). Stimulus functions of caffeine in humans: Relation to dependence potential. Neuroscience and Biobehavioral Reviews, 16, 273-287.

Henik, A. (1996). Paying attention to the Stroop effect. Fournal of the International Neuropsychological Society, 2, 467-470.

Hertz, R. S. (1999). Caffeine effects on mood and memory. Behaviour Research and Therapy, 37, 869-879.

Hindmarch, I., Quinian, P. T., Moore, K. L., \& Parkin, C. (1998). The effects of black tea and other beverages on aspects of cognition and psychomotor performance. Psychopharmacology, $139,230-238$.

Hughes, J. R., Oliveto, A. H., Bickel, W. K., Higgins, S. T., \& Badger, G. J. (1993). Caffeine self-administration and withdrawal: Incidence, individual differences and interrelationships. Drug and Alcohol Dependence, 32, 239-246.

James, J. E. (1997). Understanding caffeine: $A$ biobehavioral analysis. CA, USA: Sage.

James, J. E. (1998). Acute and chronic effects of caffeine on performance, mood, headache, and sleep. Neuropsychobiology, $38,32-41$.

Julien, R. M. (1996). A primer of drug action (6th ed.). New York: Freeman.

Kenemans, J. L., \& Verbaten, M. N. (1998). Caffeine and visuospatial attention. Psychopharmacology, 135, 353-360.

Kenemans, J. L., Wieleman, J. S. T., Zeegers, M., \& Verbaten, M. N. (1999). Caffeine and Stroop interference. Pharmacology, Biochemistry and Behavior, 63, 589-598.
Lane, J. D. (1997). Effects of brief caffeinated beverage deprivation on mood, symptoms, and psychomotor performance. Pharmacology, Biochemistry and Behavior, 58, 203-208.

Loke, W. H. (1988). Effects of caffeine on mood and memory. Physiology and Behavior, 44, 367-372.

Loke, W. H. (1990). Effects of repeated caffeine administration on cognition and mood. Human Psychopharmacology, 5, 339-348.

Lyvers, M. (2000). "Loss of control" in alcoholism and drug addiction: A neuroscientific interpretation. Experimental and Clinical Psychopharmacology, 8, 1225-249.

Lyvers, M., Boyd, G., \& Maltzman, I. (1988). Effects of cigarette smoking on bilateral electrodermal measures of the orienting reflex. Psychophysiology, 25, 408-417.

Lyvers, M., \& Maltzman, I. (1991a). Selective effects of alcohol on electrodermal indices of orienting reflexes to signal and nonsignal stimuli. Psychophysiology, 28, 559-569.

Lyvers, M. F., \& Maltzman, I. (1991b). Selective effects of alcohol on Wisconsin card sorting test performance. British fournal of Addiction, 86, 399-407.

Lyvers, M., Maltzman, I., \& Miyata, Y. (1994). Effects of cigarette smoking and smoking deprivation on Wisconsin Card Sorting Test performance. Experimental and Clinical Psychopharmacology, 2, 283-289.

Lyvers, M., \& Miyata, Y. (1993). Effects of cigarette smoking on electrodermal orienting reflexes to stimulus change and stimulus significance. Psychophysiology, 30, 231-236.

Lyvers, M., \& Yakimoff, M. (2003). Neuropsychological correlates of opioid dependence and withdrawal. Addictive Behaviors, 28, 605-611.

MacLeod, C. (1991). Half a century of research on the Stroop effect: An integrative review. Psychological Bulletin, 109, 163203.

Malloy, P. F., \& Richardson, E. D. (1994). Assessment of frontal lobe functions. Fournal of Neuropsychiatry and Clinical Neurosciences, $6,399-410$.

Maltzman, I. (1979). Orienting reflexes and classical conditioning in humans. In H. D. Kimmel, E. H. Van Olst, \& J. F. Orlebek (Eds.), Orienting reflex in humans (pp. 323-351). New York: Erlbaum.

Mathew, R. J., \& Wilson, W. H. (1985). Caffeine consumption, withdrawal and cerebral blood flow. Headache, 25, 305-309.

Meyer, F. P. (1996). Pharmacokinetic responses to caffeine in volunteers with higher scores for neuroticism. Psychopharmacology, 126, 275-276.

Milner, B. (1964). Some effects of frontal lobectomy in man. In J. M. Warren, \& K. Akert (Eds.), The frontal granular cortex and behavior (pp. 313-334). New York: McGraw-Hill.

Mountain, M. A., \& Snow, W. G. (1993). Wisconsin Card Sorting Test as a measure of frontal pathology: A review. Clinical Neuropsychology, 7, 108-118.

Nehlig, A. (1999). Are we dependent upon coffee and caffeine? A review on human and animal data. Neuroscience and Biobehavioral Reviews, 23, 563-576.

Newman, F., Stein, M. B., Trettau, J. R., Coppola, R., \& Uhde, T. W. (1992). Quantitative electroencephalographic effects of caffeine in panic disorder. Psychiatry Research: Neuroimaging, 45, $105-113$.

Osman, A., Barrios, F. X., Aukes, D., Osman, J. R., \& Markway, K. (1993). The Beck Anxiety Inventory: Psychometric properties in a community population. Foumal of Psychopathology and Behavioral Assessment, 15, 287-297.

Patat, A., Rosenzweig, P., Enslen, M., Trocherie, S., Miget, N., Bozon, M. et al. (2000). Effects of a new slow release formulation of caffeine on EEG, psychomotor and cognitive functions in sleep-deprived subjects. Human Psychopharmacology, 15, 153-170. 
Phillips-Bute, B. G., \& Lane, J. D. (1998). Caffeine withdrawal symptoms following brief caffeine deprivation. Physiology and Behavior, 63, 35-39.

Quinlan, P., Lane, J., \& Aspinall, L. (1997). Effects of hot tea, coffee and water ingestion on physiological responses and mood: The role of caffeine, water and beverage type. Psychopharmacology, 134, 164-173.

Rees, K., Allen, D., \& Lader, M. (1999). The influences of age and caffeine on psychomotor and cognitive function. Psychopharmacology; 145, $181-188$.

Richardson, N. J., Rogers, P. J., Elliman, N. A., \& O'Dell, R. J. (1995). Mood and performance effects of caffeine in relation to acute and chronic caffeine deprivation. Pharmacology, Biochemistry and Behavior, 52, 313-320.

Riedel, W., Hogervorst, E., Leboux, R., Verhey, F., Van Praag, H., \& Jolles, J. (1995). Caffeine attenuates scopolamineinduced memory impairment in humans. Psychopharmacology, $122,158-168$.

Robelin, M., \& Rogers, P. J. (1998). Mood and psychomotor performance effects of the first, but not subsequent, cup-ofcoffee equivalent doses of caffeine consumed after overnight caffeine abstinence. Behavioural Pharmacology, 9, 611-618.

Rogers, P. J., \& Dernoncourt, C. (1998). Regular caffeine consumption: A balance of adverse and beneficial effects for mood and psychomotor performance. Pharmacology, Biochemistry and Behavior, 59, $1039-1045$.

Rogers, P. J., Richardson, N. J., \& Dernoncourt, C. (1995). Caffeine use: Is there a net benefit for psychomotor performance? Neuropsychobiology, 31, 195-199.

Rusted, J. (1994). Caffeine and cognitive performance: Effects on mood or mental processing? Pharmacopsychoecologia, 7, 49-54.

Smith, A., Kendrick, A., Maben, A., \& Salmon, J. (1994). Effects of breakfast and caffeine on cognitive performance, mood and cardiovascular functioning. Appetite, 22, 39-55.
Smith, G., Perdices, M., O'Sullivan, B., Large, M., \& Barrett, N. (1997). PET study of the Wisconsin Card Sorting Test and brain activation correlates of repeated testing. Australian and New Zealand fournal of Psychiatry, 31 (Suppl.), A39.

Spielberger, C. D., Gorsuch, R. L., Lushene, R., Vagg, P. R., \& Jacobs, G. A. (1983). Manual for the State-Trait Anxiety Inventory. Palo Alto, CA: Consulting Psychologists Press.

SPSS Inc. (1999). SPSS 10.0 for Windows [Computer software]. Chicago, IL: Author.

Stewart, S. H., Karp, J., Pihl, R. O., \& Peterson, R. A. (1997). Anxiety sensitivity and self-reported reasons for drug use. Fournal of Substance Abuse, 9, 223-240.

Stuss, D. T., Benson, D. F., Kaplan, E. F., Weir, W. S., Naeser, M. A., Lieberman, I. et al. (1983). The involvement of orbitofrontal cerebrum in cognitive tasks. Neuropsychologia, 21, $235-248$.

Till, H. R., \& Lyvers, M. (2000). Effects of benzodiazepines on the frontal lobe functioning of anxiety sufferers. Australian fournal of Psychology, 52 (Suppl.), 141.

van der Stelt, O., \& Snel, J. (1998). Caffeine and human performance. In J. Snel, \& M. M. Lorist (Eds.), Nicotine, caffeine and social drinking (pp. 167-183). Amsterdam: Harwood.

Warburton, D. M. (1995). Effects of caffeine on cognition and mood without caffeine abstinence. Psychopharmacology, 119, $66-70$.

White, N. M. (1998). Cognitive enhancement: An everyday event? International fournal of Psychology, 33, 95-105.

Zahn, T. P., \& Rapoport, J. L. (1987). Autonomic nervous system effects of acute doses of caffeine in caffeine users and abstainers. International fournal of Psychophysiology, 5, 33-41. 